\title{
INFINITELY MANY SOLUTIONS FOR A FOURTH-ORDER NONLINEAR ELLIPTIC SYSTEM
}

\section{ZhenZHen Zhang, XUdong Shang And Jihui Zhang}

Abstract. In this paper we study the existence of solutions for the nonlinear elliptic system

$$
\left\{\begin{array}{l}
\Delta^{2} u-\Delta u+V_{1}(x) u=f_{u}(x, u, v), \\
\Delta^{2} v-\Delta v+V_{2}(x) v=f_{v}(x, u, v), \\
u, v \in H^{2}\left(\mathbb{R}^{N}\right) \quad x \in \mathbb{R}^{N},
\end{array}\right.
$$

where $V_{1}(x)$ and $V_{2}(x)$ are positive continue functions. Under some assumptions on $f_{u}(x, u, v)$ and $f_{v}(x, u, v)$, we prove the existence of many nontrivial high and small energy solutions by variant Fountain theorems. This generalizes the results by Y. Ye and C. Tang (J. Math. Anal. Appl. 394, 841-854, 2012) to fourth-order nonlinear elliptic system.

Mathematics subject classification (2010): 26D15, 26A51, 32F99, 41A17.

Keywords and phrases: fourth-order elliptic system, variational methods, variant Fountain theorem.

\section{REFERENCES}

[1] G.A. Afrouzi, M. Mirzapour, V.D. Radulescu, Nonlocal fourth-order kirchhoff systems with variable growth: low and high energy solutions, Collect. Math.

[2] B. Cheng, High energy solutions for the fourth-order elliptic equations in $\mathbb{R}^{N}$, Boundary Value Problems., 2014, 2014:199.

[3] Y.H. Ding, S.X. Luan, M. Willem, Solutions of a system ofdiffusion equations, J. Fixed point appl., 2, (2007), 117-139.

[4] D. HUANG, Y. LI, Multiplicity of solutions for a noncooperative $p$-Laplacian elliptic system in $\mathbb{R}^{N}$, J. Differential Equations, 215, (2005), 206-223.

[5] L. JI, C.L. TANG, Existence of solutions for the coupled systems of second and fourth order elliptic equations, Differ. Equ. Appl., 3, 2 (2011), 267-277.

[6] T. JUnG, Q.H. ChOI, Fourth order elliptic system with dirichlet boundary condition, J. Ineq. Appl 2011, 2011:60.

[7] A.C. LaZER, P.J. MCKenna, Large amplitude periodic oscillation in suspension bridge: Some new connections with nonlinear analysis, SIAM Rev., 32, (1990), 537-578.

[8] J. LIU, S.X. CHEN, X. WU, Existence and multiplicity of solutions for a class of fourth-order elliptic equations in $\mathbb{R}^{N}$, J. Math .Anal. Appl., 395, (2012), 608-615.

[9] M. Willem, Minimax Theorems, Birkh ä user, Berlin, 1996.

[10] W. WANG, A. ZANG, P. ZHAO, Multiplicity of solutions for a class of fourth-order elliptical equations, Nonlinear Anal., 70, (2009), 4377-4385.

[11] M.B. YANG, Z.F. SHEN, Infinitely many solutions for a class of fourth-order elliptic equations in $\mathbb{R}^{N}$, Acta Math. Sin.(Engl.Ser.), 24, (2008), 1269-1278.

[12] Y.W. YE, C.L. TANG, Infinitely many solutions for fourth-order elliptic equations, J. Math. Anal. Appl., 394, (2012), 841-854.

[13] Y.L. YIN, X. WU, High energy solutions and nontrivial solutions for fourth-order elliptic equations, J. Math. Anal. Appl., 375, (2011), 699-705.

[14] Y. YANG, J.H. ZHANG, Existence of solutions for some fourth-order nonlinear elliptic equations, J. Math. Anal. Appl., 351, (2009), 128-137. 
[15] Y.W. YE, C.L. TANG, Existence and multiplicity of solutions for fourth-order elliptic equations in $\mathbb{R}^{N}$, J. Math. Anal. Appl., 406, (2013), 335-351.

[16] J. H. ZHANG, Multiple solutions for some fourth-order nonlinear elliptic variational inequalities, Nonlinear Anal., 63, (2005), e23-e31.

[17] J.H. ZHANG, S.J. LI, Multiple nontrivial solutions for some fourth-order semilinear elliptic problems, Nonlinear Anal., 60, (2005), 221-230.

[18] W. ZHANG, X.H. TANG, J. ZHANG, Infinitely many solutions for fourth-order elliptic equations with general potentials, J. Math. Anal. Appl., 407, (2013), 359-368.

[19] J. ZHANG, Z.L. WEI, Infinitely many nontrivial solutions for biharmonic equations via variant fountain theorems, Nonlinear Anal., 74, (2011), 7474-7485.

[20] J. W. ZHOU, X. WU, Sign-changing solutions for some fourth-order nonlinear elliptic problems, J. Math. Anal. Appl., 342, (2008), 542-558.

[21] W. Zou, Variant fountain theorems and their applicants, Manuscripta Math., 104, (2001), 343-358. 